\title{
The analyzing of Azerbaijani pupils results of PIRLS 2016
}

\section{Author Elza Semedli}

Assoc. Prof. Khazar University, Dean School of Humanities, Education and Social Sciences. E-mail: esemedova@khazar.org

https://orcid.org/0000-0002-3831-3112

Abstract As a cognitive, emotional and psychomotor ability, the reading not a skill that people gained from birth and it is developed by the educational process. It can be also defined as a social need for humans. It is an active activity that directly affects the individual's ability to communicate with the worldview, level of knowledge, and communication skills. However, reading ability doesn`t include only rapidity, accuracy, automaticity and prosody, reading comprehension is also the most crucial part of these skills. Reading comprehension and literacy is accepted as an important skill and assessed in different grades by the different international reading literacy studies, such as PISA and PIRLS. Increasing reading literacy is one of the strategic goals besides the mathematical lliteracy for developed countries to improve at the national level in their educational policies. To improve reading literacy is also one of the national priorities in Azerbaijan. Azerbaijan has twice participated to PIRLS in 2011 and 2016. In this study is aimed to provide the comparative analysis between content standards of Azerbaijan language courses at elementary education and the PIRLS international benchmarks of reading achievement. The main purpose of the investigated study is to analysing and drawing the attention to the reading literacy abilities by Azerbaijani pupils which are needed to develop and which need to improve.

Keywords PIRLS, reading literacy, curriculum, Azerbaijani language, content standards.

DOI: 10.32906/AJES/686/2019.01.35

To cite this article:

Semedli E. (2019) The analyzing of Azerbaijani pupils results of PIRLS 2016. Azerbaijan Journal of Educational Studies. Vol. 686, Issue I, pp. 11-23.

Article history: Received — 04.01.2019; Accepted — 09.04.2019 